\title{
HICH VISCOSITY BULK-FILL GIOMER AND ORMOCER-BASED RESIN COMPOSITES: AN IN-VITRO COMPARISON OFTHEIR MECHANICAL BEHAVIOUR
}

\author{
Nicoleta Ilie ${ }^{1 \mathrm{a}^{*}}$ \\ 'Department of Operative/Restorative Dentistry, Periodontology and Pedodontics, Ludwig-Maximilians University of Munich, \\ Goethestr. 70, 80336 Munich, Germany \\ ${ }^{a}$ Dipl. Eng, PhD, Professor
}

Received: February 23, 2016 Received in revised form: February 5, 2016

Accepted: April 22,2016

Cite this article:

Published online: February 25,2016

Ilie N. High viscosity bulk-fill giomer and ormocer-based resin composites: an in-vitro comparison of their mechanical behaviour.

Stoma Edu J.2016;3(1-2):54-62.

Introduction: The paper aims to assess the mechanical properties of novel high-viscosity bulk-fill composites based on the giomer and ormocer technology, and to compare their performance with materials of the same category previously launched.

Methodology: One Giomer (Beautifil Bulk restorative/Shofu), one ormocer-based (Admira Fusion x-tra/ Voco) and the first launched bulk-fill composite (QuixFil/Dentsply) were compared to three established materials of the same category. The last (Tetric EvoCeram Bulk Fill/lvoclar Vivadent; X-tra Fil/Voco; SonicFill/Kerr) were analysed under identical conditions and were partially presented in a previous study. The mechanical properties were assessed at macroscopic (flexural strength $\sigma$ and flexural modulus $\mathrm{E}_{\text {flexural }}$ ) and microscopic scale (Martens HM and Vickers Hardness HV, indentation modulus $Y_{H U^{\prime}}$ Creep). Results: The effect of the parameter filler amount was significant on all measured properties $(p<0.001$; partial eta squared varied among $\eta_{P}^{2}=0.212\left(\right.$ Creep) and $0.891\left(Y_{H U}\right)$ ), while being higher on the modulus of elasticity $Y_{H U}\left(\eta_{P}{ }^{2}=0.891\right)$ and $E_{\text {flexural }}\left(\eta_{P}{ }^{2}=0.805\right)$. Lower $\sigma$ values were determined for the ormocer $(99.9 \pm 10.7 \mathrm{MPa})$ and giomer-based composite $(106.0 \pm 12.7 \mathrm{MPa})$, while the highest values were recorded for QuixFil, X-tra Fil and SonicFill. Significant lowest $\mathrm{E}_{\text {flexural }}$ was measured for the group Tetric

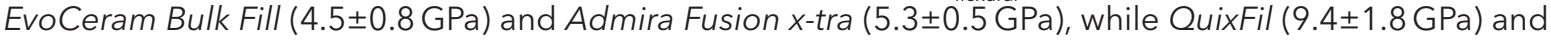
$X$-tra Fil (9.5 $\pm 0.6 \mathrm{GPa}$ ) showed statistical similar values and the highest values in the range of the analyzed materials.

Conclusions: Owing to a lower inorganic filler amount, innovative modifications such as giomers or ormocers were related to materials with moderate mechanical properties, yet comparable to values measured in regular composites.

Keywords: bulk-fill resin-based composites, strength, modulus of elasticity, hardness.

\section{Introduction}

In an effort to simplify and improve placement of direct resin-based composite (RBC) posterior restorations, manufacturers develop materials able to be cured in one 4 or even $5 \mathrm{~mm}$ thick increment. This allows to skip the time-consuming layering process and to reduce the risk of introducing failures or contaminants in-between increments. The material category is termed bulk-fill resin based composites and is classified on the basis of differences in viscosity and application technique, in low- and high-viscosity bulk-fill RBCs. The low mechanical properties of the former ${ }^{1}$ require to finish a restoration by adding a capping layer made of regular RBCs, while high-viscosity bulk-fill RBCs are intended to restore the entire preparation. Several in-vitro studies confirmed that bulk-fill RBCs may be applied in increments up to $4 \mathrm{~mm}$ thickness, ${ }^{2-5}$ when adequately cured. Besides, an acceptable marginal adaptation is reported, which is similar to that of standard RBCs. ${ }^{6}$ In a similar vein, Furness et al. ${ }^{7}$ attested a comparable proportion of gap-free tooth-restoration interfaces in either bulk-fill or conventional RBCs restorations. Yet, the proportion of gap-free interfaces tended to decrease with increasing depth in the preparation, but was largely unaffected by RBC type (one low-viscosity and three high-viscosity bulk-fill RBCs versus one nano-hybrid $\mathrm{RBC}$ ) or placement technique (4-mm bulk versus $2 \times 2-m m$ increments). In contrast to these findings, Benetti et al. ${ }^{8}$ 

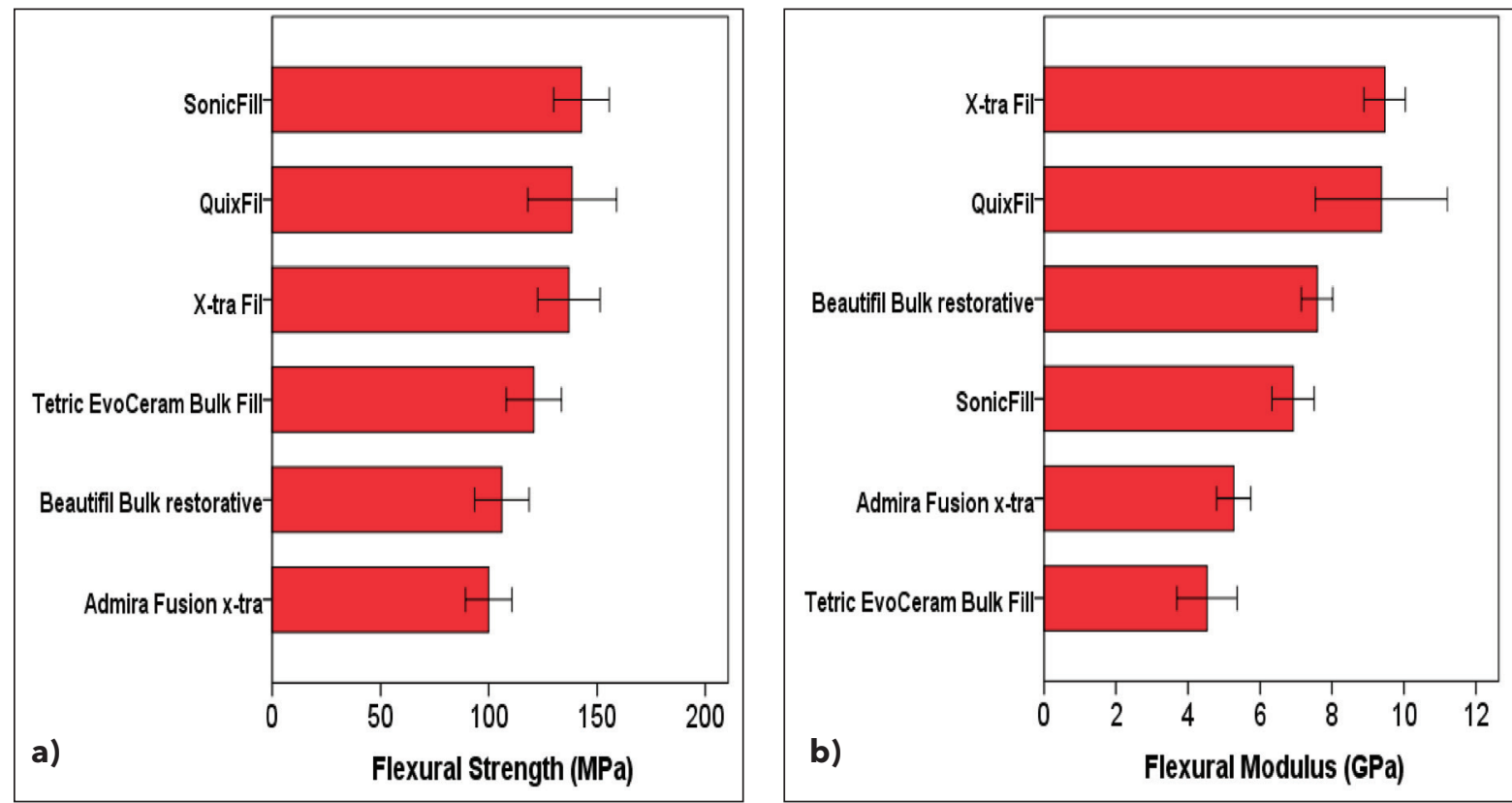

Figure 1. Macro-mechanical properties - a) Flexural strength; b) Flexural modulus

identified some bulk-fill restoratives to produced larger gaps at the dentin margin of Class II cavities, when compared to regular RBCs restorations.

Nevertheless, good in-vitro performance as reflected in improved self-leveling ability, ${ }^{9}$ decreased polymerization shrinkage stress ${ }^{10-12}$ and reduced cusp deflection ${ }^{13}$ encourage a positive forecasting of the clinical performance of bulk-fill RBCs. Owing to the short time since the materials have been launched on the market, only few clinical studies are available. For the low-viscosity bulk-fill RBC, SDR, van Dijken et al. ${ }^{14,15}$ attested in two different 3-year follow-up studies, a similar performance compared to restorations made by regular RBCs placed in a layering technique. As for high-viscosity bulk-fill RBCs, only one short 1-year clinical evaluation of class II restorations is reported so far, stating that the clinical performance of several high-viscosity bulk-fill RBCs was similar when compared to a conventional posterior RBC. ${ }^{16}$ When considering the bulk-fill RBCs as a material category, their mechanical properties were identified to fall between those of regular and flowable composites, indicating a similar or possibly inferior clinical behavior relative to standard microhybrid or nanohybrid composites. Yet, the differences in mechanical properties within the bulk-fill category were identified to be very high, which is particularly due to the different filler content. ${ }^{1}$ The performance of each material must therefore be assessed individually and cannot be transferred from the material category they belong to. Although the chemical composition of the organic matrix is largely similar to that described in regular RBCs, a particularity of bulk-fill RBCs is identified in the inorganic fillers. A lower filler content or enhanced filler size ( $>20$ $\mu \mathrm{m}$ ) was attested for several bulk-fill RBCs (x-tra fil and x-tra base, VOCO, Cuxhaven, Germany; SureFil SDR flow, DENTSPLY Caulk, Milford, DE, USA; SonicFill, Kerr, Orange, CA. USA, (1)), the result being enhanced material translucency. The changes in filler size involve a lower total fillermatrix interface compared to regular composites with lower filler size, resulting in reduced light scattering and increased light transmittance in depth. ${ }^{1}$ The aforementioned changes in fillers, but also a reduced amount of pigments are made responsible for the enhanced depth of cure of bulk-fill restoratives.

Bulk-fill composite have rapidly achieved great popularity, therefore, progressively new material options have become recently available. Innovative material developments, like new and more competitive photo-initiators ${ }^{17}$, as well as new material categories such as giomers (Glass ionomer + polymer) ${ }^{18}$ and ormocers (Organically Modified Ceramics) $)^{19}$ have recently been implemented also in high-viscosity bulk-fill RBCs. Therefore, the aim of this study was to comparatively assess the mechanical performance of novel highviscosity bulk-fill restoratives materials such as giomers and ormocers and to compare them to three established materials of the same category measured under identical conditions and partly presented in a previous study, ${ }^{1}$ by considering a battery of properties determined at both macroand microscopic scale.

The null hypotheses assume no significant difference in macro (flexural strength $(\sigma)$ and flexural modulus $\left(\mathrm{E}_{\text {flexural }}\right)$ ) and micro (Martens Hardness (HM), Vickers hardness (HV), indentation modulus ( $\left.Y_{\mathrm{HU}}\right)$, and Creep) mechanical properties among the analysed high-viscosity bulk-fill RBCs. 
Table 1. Materials, Manufacturer, chemical composition of matrix and filler as well as filler content by weight (wt.) and volume (vol.) \%

\begin{tabular}{|c|c|c|c|c|}
\hline Bulk Fill RBCs & $\begin{array}{c}\text { Manufacturer, Color, } \\
\text { Batch }\end{array}$ & Resin Matrix & Filler & Filler wt $\% / v o l \%$ \\
\hline $\begin{array}{l}\text { Tetric EvoCeram }{ }^{\circledR} \text { Bulk } \\
\text { Fill Nano-hybrid RBC }\end{array}$ & $\begin{array}{l}\text { Ivoclar Vivadent } \\
\text { IVA, P84129 }\end{array}$ & Bis-GMA, UDMA & $\begin{array}{l}\text { Ba-Al-Si-glass, prepolymer } \\
\text { filler (monomer, glass filler } \\
\text { and ytterbium fluoride), } \\
\text { spherical mixed oxide }\end{array}$ & $\begin{array}{l}79-81 \text { (including } \\
\text { 17\%prepolymers)/ } \\
60-61\end{array}$ \\
\hline $\begin{array}{c}\text { Admira Fusion x-tra } \\
\text { Nano-hybrid RBC }\end{array}$ & $\begin{array}{c}\text { Voco } \\
\text { Universal, } 1527519\end{array}$ & $\begin{array}{l}\text { Organically modified } \\
\text { silicic acid }\end{array}$ & n.s. & $84 /-$ \\
\hline $\begin{array}{c}\text { X-tra Fil } \\
\text { Hybrid RBC }\end{array}$ & $\begin{array}{c}\text { Voco } \\
\text { Universal, } 1230323\end{array}$ & Bis-GMA, UDMA, TEGDMA & n.s. & $86 / 70.1$ \\
\hline $\begin{array}{c}\text { SonicFill }{ }^{\mathrm{TM}} \\
\text { Nano-hybrid RBC }\end{array}$ & $\begin{array}{c}\text { Kerr } \\
\text { A3, } 3851737\end{array}$ & $\begin{array}{l}\text { Bis-GMA, TEGDMA, } \\
\text { EBPDMA }\end{array}$ & Si02, Glass, oxide & $83.5 /$ \\
\hline $\begin{array}{c}\text { Beautifil Bulk } \\
\text { restorative GIOMER }\end{array}$ & $\begin{array}{c}\text { Shofu Dental } \\
\text { Corporation, } \\
\text { Universal, } 11402 \\
\end{array}$ & $\begin{array}{c}\text { Bis-GMA, UDMA, } \\
\text { Bis-MPEPP, TEGDMA }\end{array}$ & $\begin{array}{c}\text { S-PRG filler based on } \\
\text { F-B-Al-Si-glass, prepolymer } \\
\text { filler }\end{array}$ & $87.0 / 74.5$ \\
\hline $\begin{array}{c}\text { QuixFil } \\
\text { Hybrid RBC }\end{array}$ & $\begin{array}{c}\text { Dentsply DeTrey } \\
\text { Universal, } \\
1209000241\end{array}$ & $\begin{array}{l}\text { Bis-EMA, UDMA, TEGDMA, } \\
\text { TMPTMA, TCB-Resin }\end{array}$ & Sr-Al-Na-F-P-Si-glass & $86 / 66$ \\
\hline
\end{tabular}

Abbreviations: Bis-GMA, bisphenol-A diglycidyl ether dimethacrylate; EBPDM/Bis-EMA, ethoxylated Bisphenol-Adimethacrylate; TEGDMA, Triethyleneglycol dimethacrylate; UDMA, Urethane dimethacrylate; TMPTMA, TrimethylolpropanTrimethacrylat; TCB resin, butane-1,2,3,4-tetracarboxylic acid, bis-2-hydroxyethyl methacrylate; Bis-MPEPP, Bisphenol A Polyethoxy-Dimethacrylat

n.s., not specified

Data are provided by manufacturers

Table 2. Influence of the parameters. Filler weight on the mechanical properties. Table contains the partial eta-square values. The higher the partial eta-square, the higher the influence of the selected factor on the measured property $(p<0.001)$

\begin{tabular}{|c|c|}
\hline Parameter & Filler weight \\
\hline$\sigma$ & 0.546 \\
\hline Eflexural & 0.805 \\
\hline HM & 0.759 \\
\hline HV & 0.596 \\
\hline YHU & 0.891 \\
\hline Creep & 0.212 \\
\hline
\end{tabular}

\section{Materials and Methods}

One giomer, one ormocer as well as the first launched high-viscosity bulk-fill RBC were compared with three established high-viscosity bulk-fill resin composites (Table 1) by assessing their mechanical properties at macroscopic ( $\sigma$ and $\left.\mathrm{E}_{\text {flexural }}\right)$ and microscopic scale $\left(\mathrm{HM}, \mathrm{HV}, \mathrm{Y}_{\mathrm{HU}}\right.$ and Creep).

\subsection{Macro-mechanical Characteristics}

The flexural strength $(\sigma)$ and flexural modulus $\left(E_{\text {flexural }}\right)$ were determined in a three-point-bending test $(n=20)$. Therefore, specimens were made by compressing the composite material between two glass plates with intermediate Polyacetate sheets, separated by a steel mold having an internal dimension of $(2 \times 2 \times 16) \mathrm{mm}$. Irradiation occurred on the top and bottom of the specimens, as specified in ISO 4049:2009 standards; ${ }^{20}$ the duration of the light exposures was 20s, with three light exposures, overlapping one irradiated section no more than $1 \mathrm{~mm}$ of the diameter of the light guide (Elipartm Freelight 2, 3M ESPE, Seefeld, Germany, 1,241 $\mathrm{mW} / \mathrm{cm}^{2}$ ) to prevent multiple polymerizations. After removal from the mold, the specimens were ground with silicon carbide sand paper (grit size P 1200/4000 (Leco)) to remove protruding edges or bulges, and then stored for $24 \mathrm{~h}$ in distilled water at $37^{\circ} \mathrm{C}$. The specimens were loaded until failure in a universal testing machine (Z 2.5, Zwick/ Roell, Ulm, Germany) in a threepoint-bending test device, which was constructed according to the guidelines of NIST No. 4877 with a $12 \mathrm{~mm}$ distance between the supports. ${ }^{21}$ During testing, the specimens were immersed in distilled water at room temperature. The crosshead speed was $0.5 \mathrm{~mm} / \mathrm{min}$. The universal testing machine measured the force during bending as a function of the deflection of the beam. The bending modulus was calculated from the slope of the linear part of the force-deflection diagram.

\subsection{Micro-mechanical Characteristics}

Fragments $(n=10)$ of the three-point-bending test specimens of each group were used to determine the micro-mechanical properties (Martens Hardness (HM), Vickers hardness (HV), indentation modulus $\left(Y_{\mathrm{HU}}\right)$ and creep) according to DIN 50359-1:1997-1022 by means of a universalhardness device (Fischerscope H100C, Fischer, Sindelfingen, Germany). Prior to testing, the 

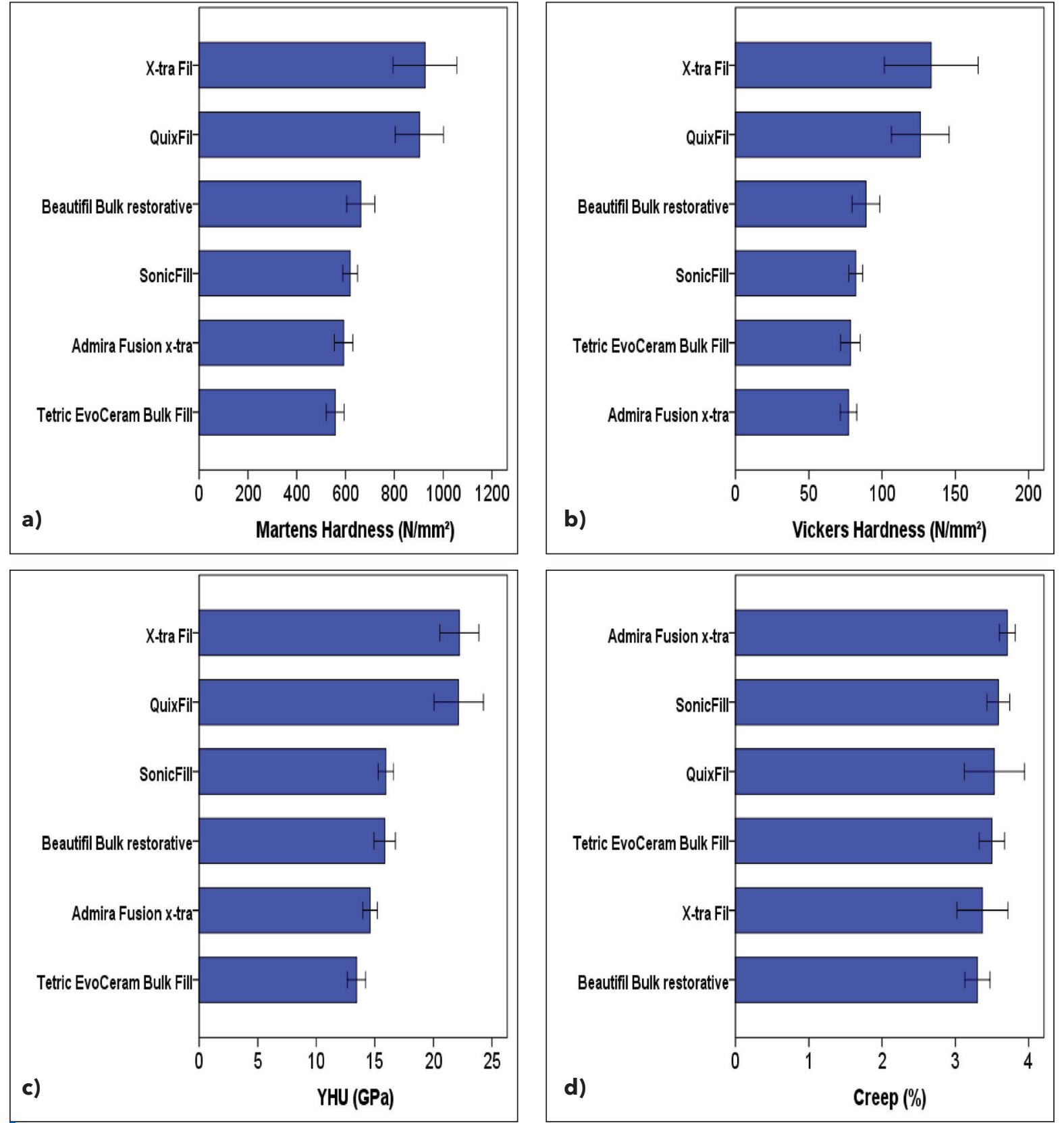

Figure 2. Micro-mechanical properties - a) Martens Hardness; b) Vickers Hardness;

c) Indentation modulus, YHU; d) Creep

specimens were polished with a grinding system (EXAKT 400 CS, EXAKT, Norderstedt, Germany) using silicon carbide paper $P 2500$ followed by $P$ 4000. Measurements were done on the top $(n=10)$ of the slabs with 6 measurements per sample. The test procedure was carried out force-controlled, where the test load increased and decreased with constant speed between 0.4 and $500 \mathrm{mN}$. The load and the penetration depth of the indenter (Vickers pyramid: diamond right pyramid with a square base and an angle of $\alpha=136^{\circ}$ between the opposite faces at the vertex) were continuously measured during the load-unload hysteresis. Universal hardness (HM) is defined as the test force divided by the apparent area of indentation under the applied test force. From a multiplicity of measurements stored in a database supplied by the manufacturer, a conversion factor (0.0945) between $\mathrm{HM}$ and $\mathrm{HV}$ was calculated by the manufacturer and entered into the software so that the measurement results were also indicated in the more familiar HV units. $Y_{H U}$ was calculated from the slope of the tangent adapted at the beginning (at maximum force) of the nonlinear indentation depth curve upon unloading. By measuring the change in indentation depth with a constant test force, a relative change in the indentation depth can be calculated. This is a value for the creep of the materials.

\subsection{Statistical Analysis}

The Kolmogoroff-Smirnoff test was applied to verify the data were normally distributed. Results were compared using one-way ANOVAs and Tukey's HSD post hoc test $(\alpha=0.05)$. A multivariate analysis (general linear model) assessed the effect 
Table 3. Macro and micromechanical properties (mean standard \pm deviation) of the bulk-fill RBCsflexural strength $\sigma(\mathrm{MPa})$, flexural modulus Eflexural (GPa), Martens Hardness $\mathrm{HM}\left(\mathrm{N} / \mathrm{mm}^{2}\right)$, Vickers Hardness HV(N/mm²), indentation modulus YHU (GPa), Creep (\%) -. Superscript letters indicate statistically homogeneous subgroups within a column (Tukey's HSD test. $\alpha=0.05$ ). * Data were partial presented in ${ }^{1}$

\begin{tabular}{|c|c|c|c|c|c|c|}
\hline & $\sigma$ & $E_{\text {flexural }}$ & HM & HV & $Y_{H U}$ & Creep \\
\hline Tetric EvoCeram Bulk Fill ${ }^{\star}$ & $120.8 \pm 12.7^{B}$ & $4.5 \pm 0.8^{a}$ & $557.3 \pm 36.4^{A}$ & $78.4 \pm 6.7^{a}$ & $13.4 \pm 0.8^{\mathrm{A}}$ & $3.5 \pm 0.2^{b c}$ \\
\hline Admira Fusion $x$-tra & $99.9 \pm 10.7^{\mathrm{A}}$ & $5.3 \pm 0.5^{\mathrm{a}}$ & $592.1 \pm 38.0^{\mathrm{AB}}$ & $77.1 \pm 5.6^{\mathrm{a}}$ & $14.6 \pm 0.6^{\mathrm{B}}$ & $3.7 \pm 0.1^{\mathrm{d}}$ \\
\hline SonicFill $^{*}$ & $142.8 \pm 12.9^{c}$ & $6.9 \pm 0.6^{b}$ & $618.6 \pm 30.1^{B}$ & $82.0 \pm 4.7^{\mathrm{ab}}$ & $15.9 \pm 0.7^{c}$ & $3.6 \pm 0.2^{\text {cd }}$ \\
\hline Beautifil Bulk restorative & $106.0 \pm 12.7^{A}$ & $7.6 \pm 0.4^{b}$ & $662.6 \pm 57.5^{c}$ & $88.9 \pm 9.5^{b}$ & $15.8 \pm 0.9$ & $3.3 \pm 0.2^{a}$ \\
\hline QuixFil & $138.6 \pm 20.5^{c}$ & $9.4 \pm 1.8^{c}$ & $902.8 \pm 98.4^{D}$ & $126.0 \pm 19.6^{c}$ & $22.2 \pm 2.1^{\mathrm{D}}$ & $3.5 \pm 0.4^{\mathrm{bc}}$ \\
\hline X-tra Fil & $137.0 \pm 14.4^{c}$ & $9.5 \pm 0.6^{c}$ & $925.6 \pm 131.1^{\mathrm{D}}$ & $133.5 \pm 32.0^{c}$ & $22.2 \pm 1.7^{D}$ & $3.4 \pm 0.3^{\mathrm{ab}}$ \\
\hline
\end{tabular}

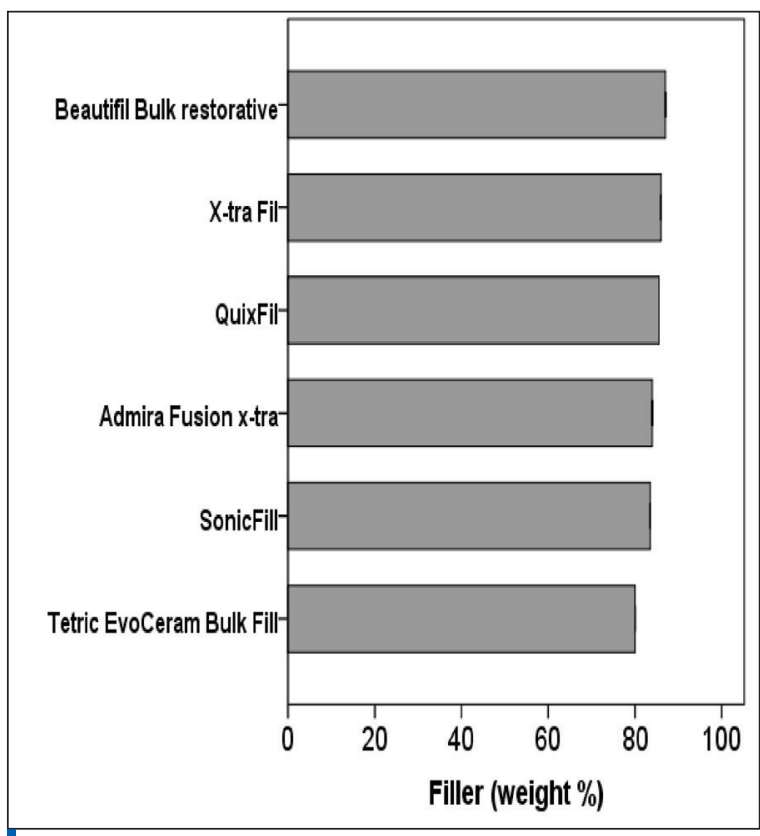

Figure 3. Filler amount (weight \%)

of the parameter filler weight on the measured parameters $\sigma$, Eflexural, HM, HV, YHU and Creep. The partial eta-squared statistic reports the practical significance of each term, based on the ratio of the variation accounted for by the effect. Larger values of partial eta-squared indicate a greater amount of variation accounted for by the model effect, to a maximum of 1 . Correlations among measured properties as well as filler amount, was assessed by a Pearson correlation analysis. In all statistical tests, $p$-values $<0.05$ were considered statistically significant when using SPSS Inc. (Version 23.0, Chicago, IL, USA).

\section{Results}

The effect of the parameter filler amount (weight $\%)$ was proved to be significant on all measured properties ( $p<0.001$; partial eta squared varied among $\eta_{P}^{2}=0.212$ for Creep and 0.891 for $Y_{H U^{\prime}}$ Table 2), while being higher on the modulus of elasticity, either measured at microscopic $\left(Y_{\mathrm{HU}} \eta_{\mathrm{P}}{ }^{2}\right.$ $=0.891)$ or macroscopic scale $\left(E_{\text {flexural; }} \eta_{p}^{2}=0.805\right)$. The direct comparison of the properties measured as a function of RBCs revealed statistical lower flexural strengths values for the ormocer-based material Admira Fusion x-tra $(99.9 \pm 10.7 \mathrm{MPa})$ and the giomer Beautifil Bulk restorative (106.0 \pm 12.7 $\mathrm{MPa})$, while the highest values were recorded for QuixFil, X-tra Fil and SonicFill. The difference in flexural strength among lowest and highest values does not exceed $40 \%$, yet differences measured for $\mathrm{E}_{\text {flexural }} \mathrm{go}$ beyond $100 \%$. The significant lowest flexural modulus was measured for the group Tetric EvoCeram Bulk Fill (4.5 $\pm 0.8 \mathrm{GPa})$ and Admira Fusion $x$-tra $(5.3 \pm 0.5 \mathrm{GPa})$, while the group QuixFil $(9.4 \pm 1.8 \mathrm{GPa})$ and $X$-tra Fil $(9.5 \pm 0.6 \mathrm{GPa})$ showed the highest values in the range of the analyzed materials. This trend is maintained also for the indentation modulus $Y_{\mathrm{HU}}$ as well as for the hardness parameters. Lower variation among materials was identified for Creep (3.3 to 3.7\%) (Table 3). The filler amount showed the best correlation with the flexural modulus (Pearson correlation coefficient $=0.724)$, followed by the indentation modulus (0.567) and the hardness parameters, while no correlation was identified with the flexural strength. An inverse correlation, yet low (-0.218) was identified between filler amount and creep. A moderate correlation was observed between the parameters measured at macroscopic scale $(\sigma$ and $\mathrm{E}_{\text {flexural' }}$ 0.425), while the correlation among the micro-mechanical parameters was high, except for Creep. The correlation among macro and micro mechanical parameters (except again for Creep) was low to moderate for $\sigma$ and high for $\mathrm{E}_{\text {flexural }}$ (Table 4).

\section{Discussion}

The basic approach of this study was to compare modern high-viscosity bulk-fill RBCs in terms of their mechanical behavior assessed at macro and microscopic scale. All materials analyzed belong to the category of high-viscosity bulk-fill RBCs, which is characterized by enhanced mechanical properties when compared to the low-viscosity bulk-fill RBCs. ${ }^{1}$ The materials analyzed are indicated to be used in bulk up to 4 or $5 \mathrm{~mm}$, to restore the entire preparation, with no need to be capped by an auxiliary restorative composite. Under the curing conditions used in the present study (20s exposure time, $1241 \mathrm{~mW} / \mathrm{cm}^{2}$ irradiance), 
Table 4. Pearson correlation coefficients among measured properties as well as filler content

\begin{tabular}{|c|c|c|c|c|c|c|c|}
\hline & weight \% & $\sigma$ & $\mathrm{E}_{\text {flexurl }}$ & $\mathrm{HM}$ & $\mathrm{HV}$ & $\mathrm{Y}_{\text {HU }}$ & Creep \\
\hline weight\% & 1 & $\mathrm{~ns}$ & 0.724 & 0.548 & 0.450 & 0.567 & -0.218 \\
\hline$\sigma$ & $\mathrm{ns}$ & 1 & 0.425 & 0.279 & 0.229 & 0.381 & $\mathrm{~ns}$ \\
\hline $\mathrm{E}_{\text {Hexural }}$ & 0.724 & 0.425 & 1 & 0.713 & 0.598 & 0.790 & $\mathrm{~ns}$ \\
\hline $\mathrm{HM}$ & 0.548 & 0.279 & 0.713 & 1 & 0.974 & 0.962 & $\mathrm{~ns}$ \\
\hline $\mathrm{HV}$ & 0.450 & 0.229 & 0.598 & 0.974 & 1 & 0.887 & $\mathrm{~ns}$ \\
\hline $\mathrm{Y}_{\text {HU }}$ & 0.567 & 0.381 & 0.790 & 0.962 & 0.887 & 1 & -0.108 \\
\hline Creep & -0.218 & $\mathrm{~ns}$ & $\mathrm{~ns}$ & $\mathrm{~ns}$ & $-\mathrm{ns}$ & -0.108 & 1 \\
\hline
\end{tabular}

the materials have proved in previous studies to be adequately polymerized in at least $4-\mathrm{mm}$ increments. ${ }^{4,5,23}$ Therefore, the macro-mechanical properties, which were assessed according to the valid standards ${ }^{20}$ on 2 -mm thick specimens, may be transferred to larger increments as well. Although low differences in filler amount were identified among the materials analyzed $(81 \%$ to $87 \%$ by weight), the inorganic filler amount was directly reflected in the measured mechanical properties, since the highest filled materials $x$-tra fil and Quixfil, which contain both 86 weight $\%$ fillers, also reached the highest mechanical properties. Table 1 indicates for Beautifil Bulk restorative an even higher filler amount (87\%). It must be pointed out that the material contains, beside inorganic bulk-filler, also large pre-polymer fillers, thus the total inorganic filler amount is accordingly lower as indicated. A similar conclusion applies for Tetric EvoCeram ${ }^{\circledR}$ Bulk Fill, in which the pre-polymer fillers amounted to $17 \%$ of the total indicated filler amount (Table 1).

All materials analyzed fulfill the ISO 4049 criteria (flexural strength $\geq 80 \mathrm{MPa}$ ) to be used in loadbearing areas as restorative materials. ${ }^{20}$ Yet, the ISO 4049 does not specify a lower limit value for the modulus of elasticity, which represents the relative stiffness of a material and is related to the deformability of a restorative material under masticatory stresses. ${ }^{24}$ Consistent larger differences among materials were identified with regard to the flexural modulus, which is directly related to the inorganic filler amount. As for the measured micromechanical properties, the present investigation revealed a strong dependence of all measured parameters on the filler amount. To assess both the elastic and the plastic part of the deformation, a depth sensing hardness measurement device was used in this study. Therefore, a dynamic measuring principle was applied by recording simultaneously the load and the corresponding penetration depth of the indenter. ${ }^{22,25}$ Besides hardness, the indentation modulus is also indicated, since previous studies attested a good correlation between indentation modulus and the modulus of elasticity measured in the more familiar threepoint bending test. ${ }^{26}$ This relation was confirmed also by the present study. While flexural modulus and indentation modulus might have attributed a similar clinical interpretation, both measured hardness parameters - Martens Hardness (or universal hardness) and the more familiar Vickers Hardness - are defined as the resistance a material oppose to penetration or indentation, and might be related to properties such as wear resistance or abrasion. ${ }^{27}$ The last statement must however be put into perspective for bulk-fill RBCs, since many bulk-fill RBCs contain larger fillers (up to $20 \mu \mathrm{m}$ ) compared to regular $\mathrm{RBCs}^{28}$ which might have a negative impact not only on the wear behaviour of the materials, but also on their aesthetic properties. The materials analyzed in the present study are the result of a large variety of innovative technologies. The concept of bulk-filling, meaning the ability to place and cure a resin-composites in large increments (up to $4 \mathrm{~mm}$ ) and thus to skip the time consuming layering technique, was first introduced with the high-viscosity bulk-fill RBC QuixFil. Yet, the low-viscosity bulk-fill RBC (SDR flow) of the same company, launched many years later, was the first bulk-fill material achieving a noticeable commercial success and establishing thus the aforementioned concept. This fact triggered a series of products from all other dental companies. As for QuixFil, the enlarge depth of cure was realized by enlarging the filler size and consequently reducing the filler-matrix interface and the scattering along this interface. Whether the refractive indices of the material components were modified in order to reduce differences among fillers and organic matrix, and therefore to reduce light scattering and enhance translucency, ${ }_{1}^{29}$ is not stated nor analyzed so far. Besides, no remarkable changes in the composition of the organic matrix or photo-initiating system are noted (Table 1).

The present study allows comparing two different bulk-fill materials from the same company $X$-tra Fil and Admira Fusion x-tra - in which two different concepts in modifying the materials for bulk-fill placement were followed. While $X$-tra Fil is based on a traditional (methacrylates) organic matrix, containing monomers like Bis-GMA, UDMA, TEGDMA (Table 1), Admira Fusion $x$-tra is a purely ormocer-based material. As different from regular di-methacrylates, Ormocers are described as 3-dimensionally cross-linked inorganic-organic polymers, synthesized from multi-functional urethane- and thioether(meth)acrylate alkoxysilanes as sol-gel precursors. Alkoxysilyl groups of silane permit 
the formation of an inorganic Si-O-Si network by hydrolysis and poly-condensation reactions, while the methacrylate groups are available for photochemical polymerization. ${ }^{19}$ The reason beneath introducing Ormocers as dental materials was motivated in their reduced polymerization shrinkage and wear when compared to regular RBCs as well as in the very similar coefficient of thermal expansion compared to the natural tooth structure. ${ }^{19}$ However, it was technically not possible for a long time to create commercial RBCs based integrally on ormocers. Therefore, ormocers were used in commercial materials only to replace parts of the regular organic matrix, which diminished the aforementioned positive effects. It might be worth mentioning that the first commercial ormocerbased restorative was Admira (Voco), launched in 1999, followed by the nano-hybrid composite Grandio of the same company. Recently, new technologies allowed creating purely ormocer RBCs, as implemented also in the analysed material Admira Fusion x-tra. With respect to the mechanical properties, the direct comparison of both bulk-fill RBCs identified consistently higher values in X-tra Fil compared to Admira Fusion $x$-tra, which is mainly attributed to the higher inorganic filler content and the enlarged filler size. The aforementioned drawbacks related to enhanced filler size must however be considered, when trying to reproduce the in-vitro data to a clinical perspective. A further interesting material development was implemented in Beautifil Bulk restorative. The material is denominated as a Giomer, an acronym derived from the main material compounds - Glass ionomer (GIC) and polymer - , since the material category contains as filler a GIC derivate, which is implemented into a resinous matrix. The fillers contained in Beautifil Bulk restorative are named S-PRG, which means surface pre-reacted glass ionomer, and were developed by Roberts et al. ${ }^{18}$ in 1999. In S-PRG, a fluoroaluminosilicate glass has been reacted with a polyalkenoic acid in the presence of water, to form a wet siliceous hydrogel. In contrast to $\mathrm{GICs}^{30}$, the acid-base reaction occurred in S-PRG fillers during manufacturing, thus resulting in a surface modified layer which is described to subsequently protect the glass core from the damaging effects of moisture. ${ }^{18}$ S-PRG fillers were proved to release and recharge fluoride but also other ions such as $\mathrm{Na}^{+}, \mathrm{Sr}^{2+}, \mathrm{Al}^{3+}, \mathrm{BO}_{3}{ }^{3-}, \mathrm{SiO}_{3}{ }^{2-31-38}$ Besides $\mathrm{S}-\mathrm{PRG}$ fillers, the material contains also large pre-polymerized filers ${ }^{4}$ comprising 87.0 weight $\%$ and 74.5 volume \%, respectively. The bulk-fill giomer restorative proved in previous in-vitro studies to be adequately cured in increments up to $4-\mathrm{mm}^{4}$ and to induce low, yet statistical similar cusp deflection compared to the ormocer based bulk-fill restorative Admira Fusion x-tra, described above.
As for Tetric EvoCeram Bulk Fill, the filler system is comparable with the filler system observed in the regular nanohybrid RBC Tetric EvoCeram. The enhanced depth of cure was realizes not by enlarging the filler size, as observed in the majority of bulk-fill RBCs, but by implementing an additional photo-initiator, Ivocerin, along with the well-known photo-initiator system camphorquinone (CQ)/ amine and an acyl phosphine oxide initiator. Ivocerin is described as a germanium-based photoinitiator with a higher photo-curing activity than $\mathrm{CQ}$, which is attributed to its larger molar extinction coefficient $(\varepsilon \lambda)$ when compared to $C Q$. Its maximal absorption is described at $411 \mathrm{~nm}$ wavelength, ${ }^{17}$ therefore the initiator may be activated by regular curing units. A further advantage of Ivocerin is that it can be used without the addition of a co-initiator (amines) as well as its ability to form at least two radicals able to initiate the radical polymerization process. Therefore, Ivocerin is considered more efficient when compared to the CQ/amine systems, in which only one radical able to initiate the polymerization reaction is formed. ${ }^{17}$

Regarding SonicFill it shows, similarly to $x$-tra fil, changes focusing primarily on the filler system, particularly on the filler size. ${ }^{1}$ A previous study identified for SonicFill specimens of thicknesses up to $6 \mathrm{~mm}$, lower blue light transmittance compared to Tetric EvoCeram Bulk Fill or $x$-tra fil. The amount of blue light transmitted is therefore comparable for SonicFill with values recorded in regular nanoand micro-hybrid RBCs. ${ }^{23}$ Although enlarged fillers were observed also in SonicFill, the material is one of the lesser bulk-fill brands offered in regular shades.

Thus, the low light transmittance might be, at least partially, attributed to the pigments' necessity to adapt the color, which are present in lower amounts in other bulk-fill RBCs, offered mainly in the color "universal" (Table 1). Compared to regular composites intended for incremental use, the analyzed bulk-fill composites revealed comparable or even superior mechanical properties. ${ }^{1}$ Nevertheless, the enhanced filler size as observed in many materials, as well as the reduced amount of pigments, may forfeit the esthetic or the wear behavior of the materials.

\section{Conclusions}

The analyzed high-viscosity bulk-fill RBCs differ consistently in the properties analyzed, which is directly related to the inorganic filler content. Innovative modifications as the giomers or ormocers were related to materials with moderate mechanical properties, yet comparable to regular RBCs. The changes in chemical composition might however create advantages in terms of polymerization shrinkage stress or a caries protective ability. 


\section{REFERENCES}

1. Ilie N, Bucuta S, Draenert M. Bulk-fill resin-based composites: an in vitro assessment of their mechanical performance. Oper Dent. 2013;38(6):618-625.

2. Czasch P, llie N. In vitro comparison of mechanical properties and degree of cure of bulk fill composites. Clin Oral Investig. 2013;17(1):227-235

3. Ilie N, Kessler A, Durner J. Influence of various irradiation processes on the mechanical properties and polymerisation kinetics of bulk-fill resin based composites. J Dent. 2013;41(8):695-702.

4. Finan L, Palin WM, Moskwa N, McGinley EL, Fleming GJ. The influence of irradiation potential on the degree of conversion and mechanical properties of two bulk-fill flowable RBC base materials. Dent Mater. 2013;29(8):906-912.

5. Garoushi S, Säilynoja E, Vallittu PK, Lassila L. Physical properties and depth of cure of a new short fiber reinforced composite. Dent Mater. 2013;29(8):835-841.

6. Garcia D, Yaman P, Dennison J, Neiva G. Polymerization shrinkage and depth of cure of bulk fill flowable composite resins. Oper Dent. 2014;39(4):441-448.

7. Alrahlah A, Silikas N, Watts DC. Post-cure depth of cure of bulk fill dental resin-composites. Dent Mater. 2014;30(2):149-154.

8. Goracci C, Cadenaro M, Fontanive L, Giangrosso G, Juloski J, Vichi A, Ferrari M. Polymerization efficiency and flexural strength of low-stress restorative composites. Dent Mater. 2014;30(6):688-694.

9. Ilie N, Fleming GJ. In vitro comparison of polymerisation kinetics and the micro-mechanical properties of low and high viscosity giomers and RBC materials. J Dent. 2015;43(7):814-822. 10. Campos EA, Ardu S, Lefever D, Jasse FF, Bortolotto T, Krejci I. Marginal adaptation of class II cavities restored with bulk-fill composites. J Dent. 2014;42(5):575-581.

11. Furness A, Tadros MY, Looney SW, Rueggeberg FA. Effect of bulk/incremental fill on internal gap formation of bulk-fill composites. J Dent. 2014;42(4):439-449.

12. Benetti AR, Havndrup-Pedersen C, Honore D, Pedersen MK, Pallesen U. Bulk-fill resin composites: polymerization contraction, depth of cure, and gap formation. Oper Dent. 2015;40(2):190-200.

13. Petrovic LM, Zorica DM, Stojanac I, Krstonosic VS, Hadnadjev MS, Atanackovic TM. A model of the viscoelastic behavior of flowable resin composites prior to setting. Dent Mater. 2013;29(9):929-934.

14. Jin $X$, Bertrand $S$, Hammesfahr P. New radically polymerizable resins with remarkably low curing stress. Journal of Dental Research. 2009;88(Spec Iss A):1651.

15. Ilie N, Hickel R. Investigations on a methacrylate-based flowable composite based on the SDRTM technology. Dent Mater. 2011;27(4):348-355.

16. El-Damanhoury H, Platt J. Polymerization shrinkage stress kinetics and related properties of bulk-fill resin composites. Oper Dent. 2014;39(4):374-382.

17. Moorthy A, Hogg CH, Dowling AH, Grufferty BF, Benetti AR, Fleming GJ. Cuspal deflection and microleakage in premolar teeth restored with bulk-fill flowable resin-based composite base materials. J Dent. 2012;40(6):500-505.

18. van Dijken JW, Pallesen U. Randomized 3-year clinical evaluation of Class I and II posterior resin restorations placed with a bulk-fill resin composite and a one-step self-etching adhesive. J Adhes Dent. 2015;17(1):81-88.
19. van Dijken JW, Pallesen U. A randomized controlled three year evaluation of "bulk-filled" posterior resin restorations based on stress decreasing resin technology. Dent Mater. 2014;30(9):e245-251.

20. Bayraktar Y, Ercan E, Hamidi MM, Colak H. One-year clinical evaluation of different types of bulk-fill composites. J Investig Clin Dent. 2016;7(1):1-9.

21. Moszner N, Fischer UK, Ganster B, Liska R, Rheinberger V. Benzoyl germanium derivatives as novel visible light photoinitiators for dental materials. Dent Mater. 2008;24(7):901-907.

22. Roberts T, Miyai K, Ikemura K, Fuchigami K, Kitamura T. Fluoride ion sustained release preformed glass ionomer filler and dental compositions containing the same. United States Patent No. 5,883,153; 1999.

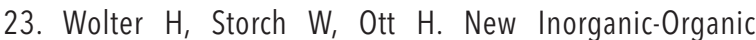
Copolymers (Ormocer(R)s) for Dental Applications. Mater Res Soc Symp Proc. (Better Ceramics through Chemistry VI). 1994;346:143-149.

24. ISO 4049:2009. Dentistry - polymer-based restorative materials; 2009.

25. Quinn GD. Room-Temperature Flexure Fixture for Advanced Ceramics, NISTIR 4877, National Institute of Standards and Technology, Gaithersburg, MD, USA; 1992.

26. DIN-50359-1. Testing of metallic materials - Universal hardness test - Part 1 : Test method; 1997.

27. Bucuta S, Ilie N. Light transmittance and micro-mechanical properties of bulk fill vs. conventional resin based composites. Clin Oral Investig. 2014;18(8):1991-2000.

28. Sabbagh J, Vreven J, Leloup G. Dynamic and static moduli of elasticity of resin-based materials. Dental Materials. 2002; 18(1):64-71.

29. Fischer-Cripps AC. Nanoindentation: dynamic indentation testing. Berlin: Springer-Verlag; 2004.

30. Ilie N, Hickel R. Macro-, micro- and nano-mechanical investigations on silorane and methacrylate-based composites. Dent Mater. 2009;25(6):810-819.

31. Anusavice KJ. in: Phillip's science of dental materials, 10th ed. Philadelphia: WB Saunders Co; 1996. p. 69

32. Nica I, Stoleriu S, Iovan G, Pancu G, Andrian S. Fractal analysis of some restorative Nano-filled composite materials microstructure. Stoma Edu J. 2015;2(1):36-43.

33. Azzopardi N, Moharamzadeh K, Wood DJ, Martin N, van Noort R. Effect of resin matrix composition on the translucency of experimental dental composite resins. Dent Mater. 2009;25(12):1564-1568.

34. Basso M, Brambilla E, Benites M, Giovannardi M, Ionescu A. Glassionomer cement for permanent dental restorations: a 48-months, multi-centre, prospective clinical trial. Stoma Edu J. 2015;2(1):25-35.

35. Fujimoto Y, Iwasa M, Murayama R, Miyazaki M, Nagafuji A, Nakatsuka T. Detection of ions released from S-PRG fillers and their modulation effect. Dent Mater J. 2010;29(4):392-7.

36. Han L, Okamoto A, Fukushima M, Okiji T. Evaluation of a new fluoride-releasing one-step adhesive. Dent Mater J. 2006;25(3):509-515

37.Itota T, Al-Naimi OT, Carrick TE, Yoshiyama M, McCabe JF. Fluoride release from aged resin composites containing fluoridated glass filler. Dent Mater. 2005;21(11):1033-1038. 38. Ikemura K, Tay FR, Kouro Y, Endo T, Yoshiyama M, Miyai K, et 
al. Optimizing filler content in an adhesive system containing pre-reacted glass-ionomer fillers. Dent Mater. 2003;19(2):137146.

39. Tay FR, Sano H, Tagami J, Hashimoto M, Moulding KM, Yiu

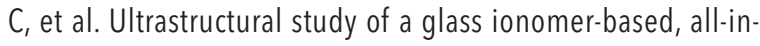
one adhesive. J Dent. 2001;29(7):489-498.

40. Hahnel S, Wastl DS, Schneider-Feyrer S, Giessibl FJ, Brambilla E, Cazzaniga G, et al. Streptococcus mutans biofilm formation and release of fluoride from experimental resin- based composites depending on surface treatment and S-PRG filler particle fraction. J Adhes Dent. 2014;16(4):313-321.

41. Shimazu K, Ogata K, Karibe H. Evaluation of the ionreleasing and recharging abilities of a resin-based fissure sealant containing S-PRG filler. Dent Mater J. 2011;30(6):923927.

42. Han L, Okiji T. Evaluation of the ions release / incorporation of the prototype S-PRG filler-containing endodontic sealer. Dent Mater J. 2011;30(6):898-903.

\section{Nicoleta ILIE \\ Dipl. Eng, PhD, Professor Department of Operative/Restorative Dentistry, Periodontology and Pedodontics Ludwig-Maximilians University of Munich, Goethestr. 70, 80336 Münich, Germany}

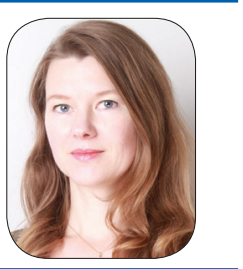

Studies of "Technology of silicates and high temperature oxides" at the "Traian Vuia" University, Temeschburg, Romania (1989-1993). Studies of material sciences with focus on glass and ceramics at the Friedrich Alexander University, Erlangen-Nürnberg, Germany (1994-1999).

Doctoral degree in material sciences from the Ludwig-Maximilians-University, Dental School, Münich, Germany (1999-2004), followed by postdoctoral lecture qualification (habilitation) at the same university (2004-2009). Since 1999, assistant professor, associated professor (2009) and professor (2014) for biomaterials at the Dental School of the Ludwig-Maximilians-University in Münich.

\section{Orestions}

\section{The difference between a bulk-fill and a regular resin composite is given by:}

a. Incremental thickness, which is ca. 2-mm for regular composites and up to 4-5-mm for bulk-fill composites;

$\square$ b. Chemical composition of the organic matrix and filler system;

c. Way to be cure;

$\square$ d. Mechanical properties.

\section{Bulk-fill resin composites are subdivided with respect to following particularities:}

$\square$ a. Bulk-fill composites are a unitary material category, with less difference among individual materials;

b. Mechanical properties: low-viscosity bulk-fill resin composites are characterized by lower mechanical properties compared to high-viscosity bulk-fill resin composites ;

$\square$ c. Application technique: low-viscosity bulk-fill resin composites need to be finished by an additional layer of a regular resin composite, while high-viscosity bulk-fill resin composites are intended to restore the entire preparation;

$\square$ d. Incremental thickness .

\section{What are "Giomers" ?}

$\square$ a. Resin-based composites with particular glass ionomer filler ;

$\square$ b. Resin-based composites able to release ions like F-;

$\square$ c. Glass ionomers, and therefore this material category does not need to be cure by blue light;

$\square$ d. A sort of ceramic.

\section{What are "Ormocers" ?}

a. 3-dimensionally cross-linked inorganic-organic polymers ;

$\square$ b. A purely inorganic material;

$\square$ c. A purely organic material;

$\square$ d. A material able to release F- . 